University of New Hampshire

University of New Hampshire Scholars' Repository

\title{
$9-2009$
}

\section{Near-surface remote sensing of spatial and temporal variation in canopy phenology}

Andrew D. Richardson

University of New Hampshire, andrew.richardson@unh.edu

Rob Braswell

University of New Hampshire - Main Campus, rob.braswell@unh.edu

David Y. Hollinger

USDA Forest Service

J P. Jenkins

University of New Hampshire - Main Campus

Scott V. Ollinger

University of New Hampshire - Main Campus, scott.ollinger@unh.edu

Follow this and additional works at: https://scholars.unh.edu/earthsci_facpub

\section{Recommended Citation}

Richardson, A. D., Braswell, B. H., Hollinger, D. Y., Jenkins, J. P. and Ollinger, S. V. (2009), Near-surface remote sensing of spatial and temporal variation in canopy phenology. Ecological Applications, 19:

1417-1428. doi:10.1890/08-2022.1

This Article is brought to you for free and open access by the Earth Sciences at University of New Hampshire Scholars' Repository. It has been accepted for inclusion in Earth Sciences Scholarship by an authorized administrator of University of New Hampshire Scholars' Repository. For more information, please contact Scholarly.Communication@unh.edu. 


\title{
Near-surface remote sensing of spatial and temporal variation in canopy phenology
}

\author{
Andrew D. Richardson, ${ }^{1,3}$ Bobby H. Braswell, ${ }^{1}$ David Y. Hollinger, ${ }^{2}$ Julian P. Jenkins, ${ }^{1}$ \\ AND SCOTT V. Ollinger ${ }^{1}$ \\ ${ }^{1}$ University of New Hampshire, Complex Systems Research Center, Morse Hall, 39 College Road, Durham, New Hampshire 03824 USA \\ ${ }^{2}$ USDA Forest Service, Northern Research Station, 271 Mast Road, Durham, New Hampshire 03824 USA
}

\begin{abstract}
There is a need to document how plant phenology is responding to global change factors, particularly warming trends. "Near-surface" remote sensing, using radiometric instruments or imaging sensors, has great potential to improve phenological monitoring because automated observations can be made at high temporal frequency. Here we build on previous work and show how inexpensive, networked digital cameras ("webcams") can be used to document spatial and temporal variation in the spring and autumn phenology of forest canopies. We use two years of imagery from a deciduous, northern hardwood site, and one year of imagery from a coniferous, boreal transition site. A quantitative signal is obtained by splitting images into separate red, green, and blue color channels and calculating the relative brightness of each channel for "regions of interest" within each image. We put the observed phenological signal in context by relating it to seasonal patterns of gross primary productivity, inferred from eddy covariance measurements of surface-atmosphere $\mathrm{CO}_{2}$ exchange. We show that spring increases, and autumn decreases, in canopy greenness can be detected in both deciduous and coniferous stands. In deciduous stands, an autumn red peak is also observed. The timing and rate of spring development and autumn senescence varies across the canopy, with greater variability in autumn than spring. Interannual variation in phenology can be detected both visually and quantitatively; delayed spring onset in 2007 compared to 2006 is related to a prolonged cold spell from day 85 to day 110. This work lays the foundation for regional- to continental-scale camera-based monitoring of phenology at network observatory sites, e.g., National Ecological Observatory Network (NEON) or AmeriFlux.
\end{abstract}

Key words: AmeriFlux; autumn color; Bartlett Experimental Forest, New Hampshire, USA; eddy covariance; Howland Forest, Maine, USA; phenology; RGB image analysis; spring onset; webcam.

\section{INTRODUCTION}

Long-term phenological observations from North America, Europe, and Asia provide indisputable evidence that climate change (particularly recent warming trends) is affecting the timing of life-cycle events of species from a diverse range of taxonomic groups (Peñuelas et al. 2002, Schwartz et al. 2006, Cleland et al. 2007, Parmesan 2007). At the same time, experimental studies have shown how other global change factors (e.g., elevated $\mathrm{CO}_{2}$ and $\mathrm{N}$ deposition) can also influence phenology (e.g., Cleland et al. 2006). The recent establishment of the USA National Phenology Network (USA-NPN; more information available online), ${ }^{4}$ "citizen science" efforts such as ProjectBudBurst (more information available online), ${ }^{5}$ and the GLOBE phenology project (Gazal et al. 2008) all signal a perceived need to better document biological responses to a changing

Manuscript received 31 October 2008; accepted 9 January 2009. Corresponding Editor: M. Friedl.

${ }^{3}$ E-mail: andrewr@solo.sr.unh.edu

${ }^{4}$ 〈http://www.usanpn.org

5 〈http://www.budburst.org $\rangle$ world, and highlight the importance of phenological monitoring to achieve this goal (Morisette et al. 2009).

Traditional plant phenology relies on direct human observations of discrete phenological events, or phenophases, such as budburst and flowering (e.g., Lechowicz 1984, Richardson et al. 2006). Such observations are typically made on a limited number of individual organisms, across a limited geographic area (i.e., often at a specific research site). Land surface phenology, on the other hand, uses satellite remote sensing to quantify seasonal patterns of development and senescence of vegetation at coarse spatial and temporal resolution, but at a regional or larger scale (White and Nemani 2006).

Intermediate between these two extremes is "nearsurface" remote sensing of phenology, whereby radiometric instruments or imaging sensors are used to quantify, at high temporal resolution, and with some degree of spatial integration (i.e., the potential to look across the canopy as a whole, rather than focus on individual organisms), seasonal changes in the optical properties of vegetated surfaces (e.g., Jenkins et al. 2007, Richardson et al. 2007). Recent studies have demonstrated that digital cameras, although not certified as calibrated instruments, can be used successfully as 
relatively inexpensive, multi-channel imaging sensors (Graham et al. 2006, 2009, Richardson et al. 2007, Ahrends et al. 2008, Crimmins and Crimmins 2008). For example, in previous work (Richardson et al. 2007), we used a networked digital camera ("webcam"), mounted at the top of an instrument tower in a maple-beechbirch hardwood stand at the Bartlett Experimental Forest (New Hampshire, USA), to obtain images of the canopy each day between 12:00 and 14:00 hours. We demonstrated that, for a prespecified "region of interest," the relative brightness of the red, green and blue (RGB) channels could be used to construct indices that tracked spring canopy development and closely paralleled the phenology signal as inferred from aboveand below-canopy radiometric instruments.

Here, we build on our earlier work. We use two years of archived webcam imagery to characterize seasonal patterns of green-up and senescence at Bartlett. We investigate variation in the timing and rate of phenological changes, both in terms of temporal (year-to-year) and spatial (across the canopy) variation. We also conduct an analysis of one year of archived webcam images from the conifer-dominated Howland Forest (Maine, USA), to investigate seasonal patterns of variation in an evergreen canopy. These results are related to estimates of canopyscale photosynthesis derived from eddy covariance measurements of surface-atmosphere $\mathrm{CO}_{2}$ exchange.

Digital imaging has previously been used for both agricultural (e.g., Hague et al. 2006, Slaughter et al. 2008) and ecological monitoring (e.g., Luscier et al. 2006, Booth and Cox 2008) applications. However, the analysis presented here is particularly relevant given opportunities within the National Ecological Observatory Network (NEON) and also Long-Term Ecological Research (LTER) and AmeriFlux networks, to implement automated and continuous regional- to continental-scale monitoring of phenology using inexpensive imaging technologies. The resulting data will be of value to both ecologists, environmental scientists, and land managers, with respect to (1) documentation and interpretation of ecosystem-level phenological responses to climate change; (2) validation and improvement of satellite-based phenology products; and (3) integration of phenological forecasting into adaptive management programs related to both natural resources (e.g., agriculture and forestry) and also human health (e.g., allergens and disease vectors) (Cleland et al. 2007, Morisette et al. 2009).

\section{Data AND Methods}

\section{Study sites}

Research was conducted at the Bartlett Experimental Forest $\left(44^{\circ} 3^{\prime} 52.7^{\prime \prime} \mathrm{N}, 71^{\circ} 17^{\prime} 17.1^{\prime \prime} \mathrm{W}, 270 \mathrm{~m}\right.$ above sea level) and Howland Forest $\left(45^{\circ} 12^{\prime} 14.7^{\prime \prime} \mathrm{N}, 68^{\circ} 44^{\prime} 25.0^{\prime \prime}\right.$ $\mathrm{W}, 60 \mathrm{~m}$ above sea level). Forest composition at Bartlett is dominated by northern hardwood species, red maple (Acer rubrum, 28\% basal area) and American beech (Fagus grandifolia, 20\%), but features a substan- tial eastern hemlock (Tsuga canadensis, 17\%) component. Other hardwoods (primarily paper birch, Betula papyrifera, yellow birch, Betula alleghaniensis, and bigtooth aspen, Populus grandidentata) account for $31 \%$ of basal area, and other conifers for $4 \%$ of basal area. At Howland, which is located about $230 \mathrm{~km}$ to the northeast of Bartlett, dominant species are the evergreen conifers red spruce (Picea rubens, 44\%) and hemlock $(26 \%)$, with lesser quantities of other conifers (21\%; primarily white cedar, Thuja occidentalis, and white pine, Pinus strobus) and mixed hardwoods (9\%; primarily red maple and paper birch). Sites are described in greater detail elsewhere (Bartlett, Richardson et al. 2007; Howland, Hollinger et al. 2004).

Both Bartlett and Howland are part of the AmeriFlux network (more information available online). ${ }^{6}$ At each site $\mathrm{a} \approx 30 \mathrm{~m}$ high tower is instrumented for eddy covariance measurements of surface-atmosphere exchanges of $\mathrm{CO}_{2}$, $\mathrm{H}_{2} \mathrm{O}$, and energy. Flux measurement procedures are described fully by Hollinger et al. (2004). The method for partitioning measured net exchange to gross primary productivity and ecosystem respiration is described by Richardson et al. (2007) and evaluated by Desai et al. (2008). At Bartlett, a comprehensive suite of radiometric instruments (described by Jenkins et al. 2007) is used to measure incident solar radiation (shortwave radiation in $\mathrm{W} / \mathrm{m}^{2}$, as well as direct and diffuse photosynthetic photon flux density, PPFD, in $\mu \mathrm{mol} \cdot \mathrm{m}^{-2} \cdot \mathrm{s}^{-1}$ ), canopy reflected radiation (shortwave and PPFD), and canopy transmitted radiation (PPFD only).

We mounted networked digital webcams (Bartlett, model 211, Axis Communications, Lund, Sweden; Howland, model Netcam XL, StarDot Technologies, Buena Park, California) near the top of each tower, looking north, and angled slightly downward, providing a view across the top of the canopy (Fig. 1). At Bartlett, the Axis camera features a Sony Corporation (San Diego, California, USA) one-quarter-inch $(\sim 0.635 \mathrm{~cm})$ Wfine progressive scan CCD image sensor and $640 \times$ 480 pixel output, whereas the StarDot camera at Howland features a Micron (Boise, Idaho, USA) onehalf-inch $(\sim 1.27 \mathrm{~cm})$ CMOS active-pixel digital image sensor and $1024 \times 768$ pixel output. Digital images, recorded between 12:00 and 14:00 hours at Bartlett, and around the clock at Howland, were archived as minimally compressed JPEGs, with three channels (red, green, and blue; corresponding to the "standard model" of additive color reproduction) of eight-bit RGB color information, for subsequent processing. Here, we restrict our analysis to the RGB color space (alternative models of color representation, e.g., HSL: hue, saturation, and luminance, have been used in some previous studies and appear to offer promise; see Crimmins and Crimmins 2008, Graham et al. 2009), as this is the native format of JPEG images.

\footnotetext{
${ }^{6}\langle$ http://public.ornl.gov/ameriflux/ $\rangle$
} 

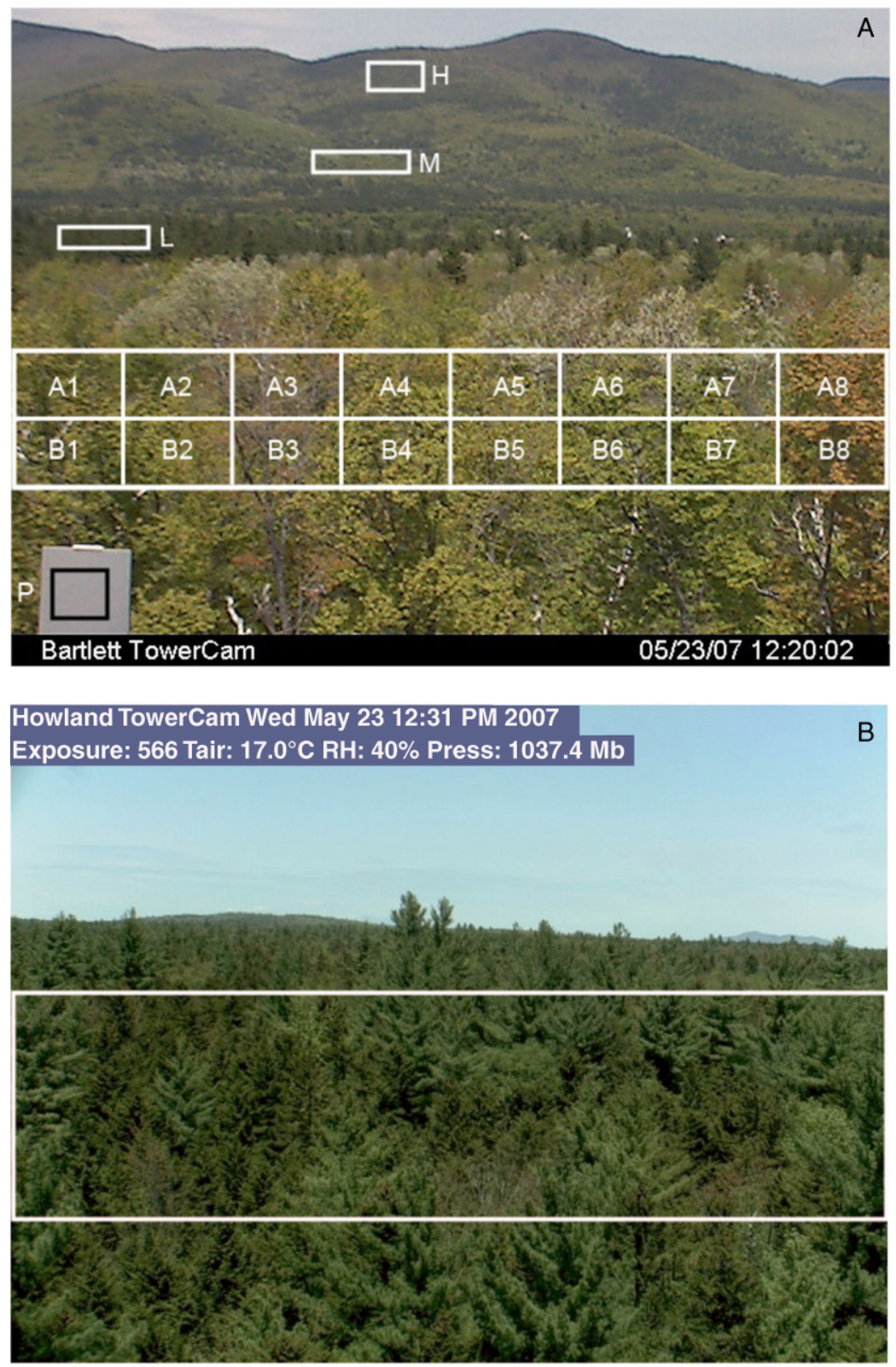

FIG. 1. Sample images (both recorded 23 May 2007) from webcams in (A) the Bartlett Experimental Forest (New Hampshire, USA) and (B) the Howland Forest (Maine, USA). In panel (A), the main region of interest (ROI), and its 16 subregions, are indicated, as are supplementary ROIs in a low-elevation white pine stand (L), and mid- and high-elevation mixed stands (M and H, respectively). The gray reference panel (see Methods) is visible in the lower left-hand corner. For Howland, only a single ROI, as indicated, was analyzed.

\section{Image processing}

We used a script to process and analyze the archived digital image files in MATLAB (R2007b; The MathWorks, Natick, Massachusetts). Images were sequentially read, and the date and time at which each picture was taken were parsed from the file name. Analysis was conducted on specific "regions of interest" (ROIs), as illustrated in Fig. 1. The ROI for each site spanned the full width of the picture and extended vertically from pixel 250 to 350 (Bartlett) and from pixel 335 to 600 (Howland). The ROI at Bartlett was selected to maximize the amount of deciduous forest canopy included for analysis, while avoiding mountains and sky above the ROI and understory or forest floor (covered by snow in winter) below the ROI. The ROI at Howland was dominated by conifer species, with only a few red maple and paper birch trees included.

To quantify patterns of spatial variation at Bartlett, the ROI was divided into 16 subregions (each $80 \times$ 


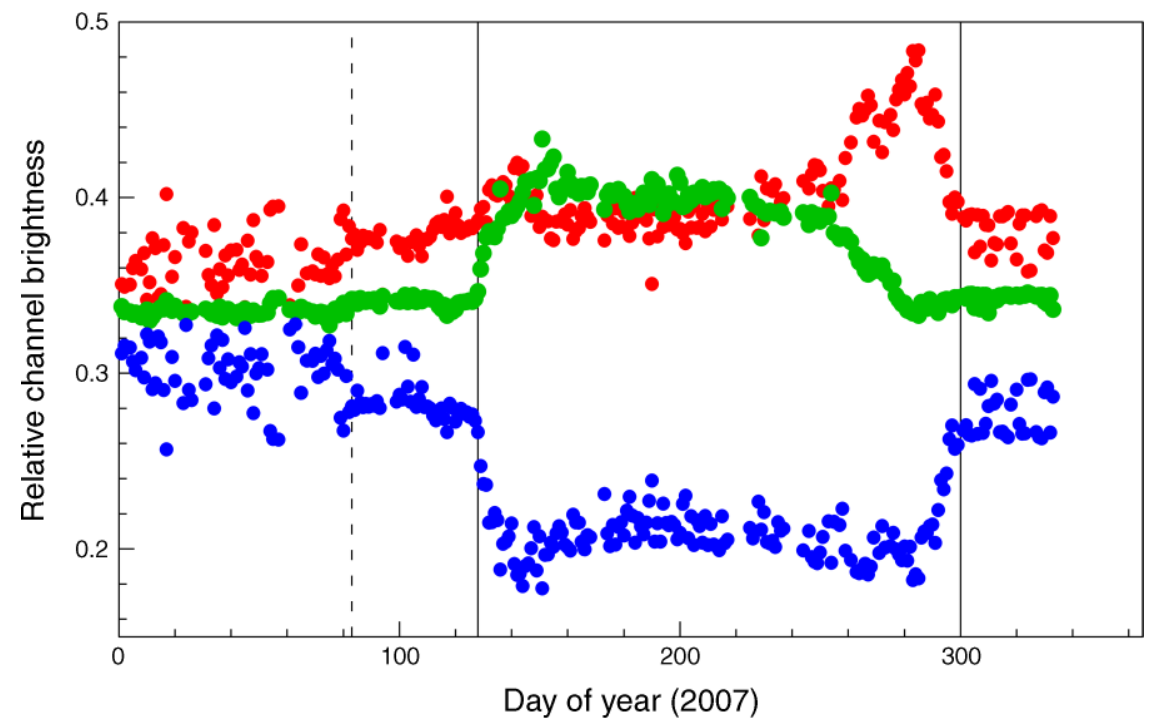

FIG. 2. Seasonal patterns of relative color channel brightness (red\%, green $\%$ and blue $\%$ ), from digital webcam imagery at Bartlett (note that the index is actually calculated as a proportion, but we call it "percent" for convenience). The dashed line at day 83 indicates the date when the camera was switched from auto white balance to fixed white balance. The solid lines denote total canopy duration, from the first leaf out to the last leaf dropped.

50 pixels in size), and each of these regions analyzed separately. We also identified three smaller ROIs, centered on a valley-bottom white pine stand roughly $1 \mathrm{~km}$ from the tower $(65 \times 15$ pixels $)$, and, on a hill roughly $3 \mathrm{~km}$ distant, mixed deciduous-conifer stands at mid $(\approx 300 \mathrm{~m}$ above sea level; $70 \times 15$ pixels $)$ and high $(\approx 600 \mathrm{~m}$ above sea level; $40 \times 20$ pixels) elevations.

Camera color channel information (digital numbers; DNs) was extracted from the JPEG file and averaged across the ROI, and then across multiple images on a given day, for each of the three separate color channels (red DN, green DN and blue DN). The overall brightness (i.e., total RGB DN) of the ROI was calculated as in Eq. 1, and was then used to calculate the relative (or normalized) brightness of each channel (i.e., channel\%; note that the index is actually calculated as a proportion, but we call it "percent" for convenience) in Eq. 2:

$$
\begin{aligned}
\text { total } \mathrm{RGB} D \mathrm{DN} & =\text { red } \mathrm{DN}+\text { green } \mathrm{DN}+\text { blue } \mathrm{DN} \\
\text { channel } \% & =\frac{\text { channel DN }}{\text { total RGB DN }} .
\end{aligned}
$$

Diurnal variation in relative channel brightness was negligible at Bartlett, but more pronounced at Howland. On sunny days in midsummer at Bartlett, relative brightness for each channel varied little between sunrise and sunset, and was extremely stable between 07:30 and 16:00 hours. By comparison, at Howland, red\% (and to a lesser degree, green $\%$ and blue\%) varied dramatically over the course of the day in a manner that is suggestive (e.g., red at a maximum early and late in the day, smoothly descending to a minimum near 12:00 hours) of the effects related to solar elevation and azimuth coupled with viewing geometry and shadow effects (similar diurnal patterns were reported by Ahrends et al. [2008], but were less symmetric presumably because in that study the camera was pointed west, and shadowing was more pronounced). In spite of this variation, relative brightness for each channel was essentially stable between 10:30 and 13:30 hours at Howland. For this reason, our analysis here is based only on midday imagery.

\section{Quality control}

After finding (Richardson et al. 2007) that day-to-day variation in color balance of camera images was related to changes in the quality of incident solar radiation, we set both cameras to "fixed white balance"; as can be seen in Fig. 2 (compare also with Fig. 3 in Richardson et al. 2007), this reduced the day-to-day variability of all three color channels, particularly blue\%. At the same time, we mounted a small plastic panel, spray painted with matte gray primer (yielding roughly equal relative brightness values of $0.34,0.34$, and 0.32 for red\%, green $\%$ and blue $\%$, respectively; compare with the white panel used by Ahrends et al. 2008, which tended to be fully saturated on sunny days), in the lower left corner of the Bartlett image (visible in Fig. 1A, the black square in the middle of the panel denotes the area we analyzed quantitatively; a similar panel was not installed at Howland until 2008). Positioned so as not to be shaded by the tower frame at midday, we intended to use this as an uncalibrated "color standard" with which we could better judge the day-today stability of the imagery color balance. For the panel itself, the overall brightness (DN) of each channel varied (one standard deviation) by more than $20 \%$ from day to day, but corresponding relative channel brightness 
values varied by $<0.010$ for red\% and blue\% (i.e., by $\approx 2.5 \%$ of the mean relative brightness), and by $<0.003 \%$ for green $\%$ (i.e., $\approx 1.0 \%$ of the mean relative brightness), giving us confidence in the quality of the retrieved signal.

Unless otherwise noted, images used in the analysis presented here were not filtered for adverse weather conditions. For Bartlett, we found the timing of seasonal inflection points (e.g., spring and autumn dates of halfmaximum green $\%$, and date of peak autumn red\% for the main ROI) was highly consistent, and within uncertainty estimates, regardless of whether it was a sunny, cloudy, or rainy day. At Howland, greater variability day-to-day variability was observed, and while we developed methods (described below) to filter out dark images recorded on overcast days, seasonal patterns were robust even without this filtering.

\section{Characterizing seasonal patterns}

To characterize the timing and rate of seasonal phenological changes, e.g., spring green-up and autumn senescence, we have previously fit a simple sigmoidshaped logistic function (e.g., Richardson et al. 2006) separately to the data for each season. An alternative method uses two sigmoid functions multiplied together, as shown here:

$$
g(x)=a+\frac{b}{[1+\exp (c-d x)] \times[1+\exp (e-f x)]} .
$$

Here, $g(x)$ is some index of phenological state, $x$ is the driving variable (in this case, day of year), and $a$ through $e$ are fit parameters. Parameter $a$ gives the base level (e.g., dormant season value) of $g(x)$, and parameter $b$ gives the seasonal amplitude of $g(x)$. Parameters $c$ and $d$ control the timing and rate of increase in the "rising" part of the seasonal trajectory, and $e$ and $f$ control the timing and rate of decrease in the "falling" part of the seasonal trajectory (provided that appropriate starting values and bounds have been specified for parameters $c$ through $f$ ). The values of $x$ at which $g(x)$ equals its half maximum (i.e., when $g(x)=a+b / 2$ ) are given by $c / d$ and $e / f$.

\section{Results AND Discussion}

\section{Seasonal patterns of a deciduous canopy}

Consistent with results reported previously (Richardson et al. 2007), we found at Bartlett that the relative channel brightness (e.g., red\%, blue\%, and green\%; Fig. 2) yielded more distinct seasonal signals than the absolute channel brightness, because in spite of autoexposure routines within the camera, absolute image brightness is confounded by day-to-day variation in solar irradiance, e.g., a bright, sunny day vs. a dark, overcast day.

Both red $\%$ and blue\% were more variable from day-today than green\%. Changes in the spectral quality of solar irradiance, due, for example, to aerosols, predominantly affects blue wavelengths, and somewhat less so green wavelengths, but the aggregate shift in blue $\%$ and green $\%$ must be offset by corresponding changes in red\%, since relative channel brightness values sum to 1 . Overall, however, the seasonal changes in relative channel brightness driven by changes in canopy state were larger than the day-to-day variations caused by variation in atmospheric conditions.

The seasonal patterns differed for each of the three color channels. In 2007, green\% remained stable throughout the winter and early spring, but began rising at approximately day 128 . This inflection point (marked by the first solid vertical line in Fig. 2) corresponds to leaf-out by beech and red maple, which, from ground-based observer records and visual inspection of the camera images (as well as measurements of the fraction of incident solar radiation transmitted through the canopy), occurred between day 127 and day 129. Beginning at the same time, and lasting for about two weeks, there was also a small rise, and then fall, in red\%, apparently reflecting flowering by red maple trees, and thus indicating the potential for using webcam imagery to characterize reproductive phenology as well (see also Crimmins and Crimmins, 2008). Since pollen release accompanies flowering, it is conceivable that webcam monitoring of flowering phenology in diverse ecosystems could make an important contribution to both mapping of, and developing predictive models for human exposure to, allergenic pollens.

Green\% reached a flat summer plateau by day 150 , but began to decline as early as day 210 , at which time a visible yellowing of the canopy began to occur. As late summer transitioned into autumn, the decline in green $\%$ became more rapid, as leaf pigmentation of species like red maple shifted from being dominated by chlorophylls to xanthophylls and anthocyanins (e.g., Lee et al. 2003). This was reflected by a concurrent rise in red\%, beginning around day 250 . By day 280 , autumn leaf coloration (and red\%) was at peak, while green\% had receded to dormant-season levels. Over the next three weeks, red\% dropped as autumn colors began to fade and abscission occurred. By day 300 (marked by the second solid vertical line in Fig. 2), when the decline in red\% was complete, transmittance measurements indicated that the canopy was essentially bare.

Although blue $\%$ was quite variable from day to day, it nevertheless followed a clear seasonal pattern that mirrored the combined seasonal changes in red\% and green $\%$, declining with canopy development in spring and then rising with abscission in autumn. Indeed, of the three color channels, blue\% was the only one linearly correlated $(r=0.90, P<0.001)$ with canopy leaf area index (LAI), which we estimated, following Turner et al. (2003), from radiometric measurements of canopy transmittance and application of the Beer-Lambert law. By comparison, the relationship between green $\%$ and LAI, while strong in the spring $(r=0.97, P<0.001$ between day 60 and day 180) exhibited pronounced seasonal hysteresis, largely due to the fact that in autumn, 

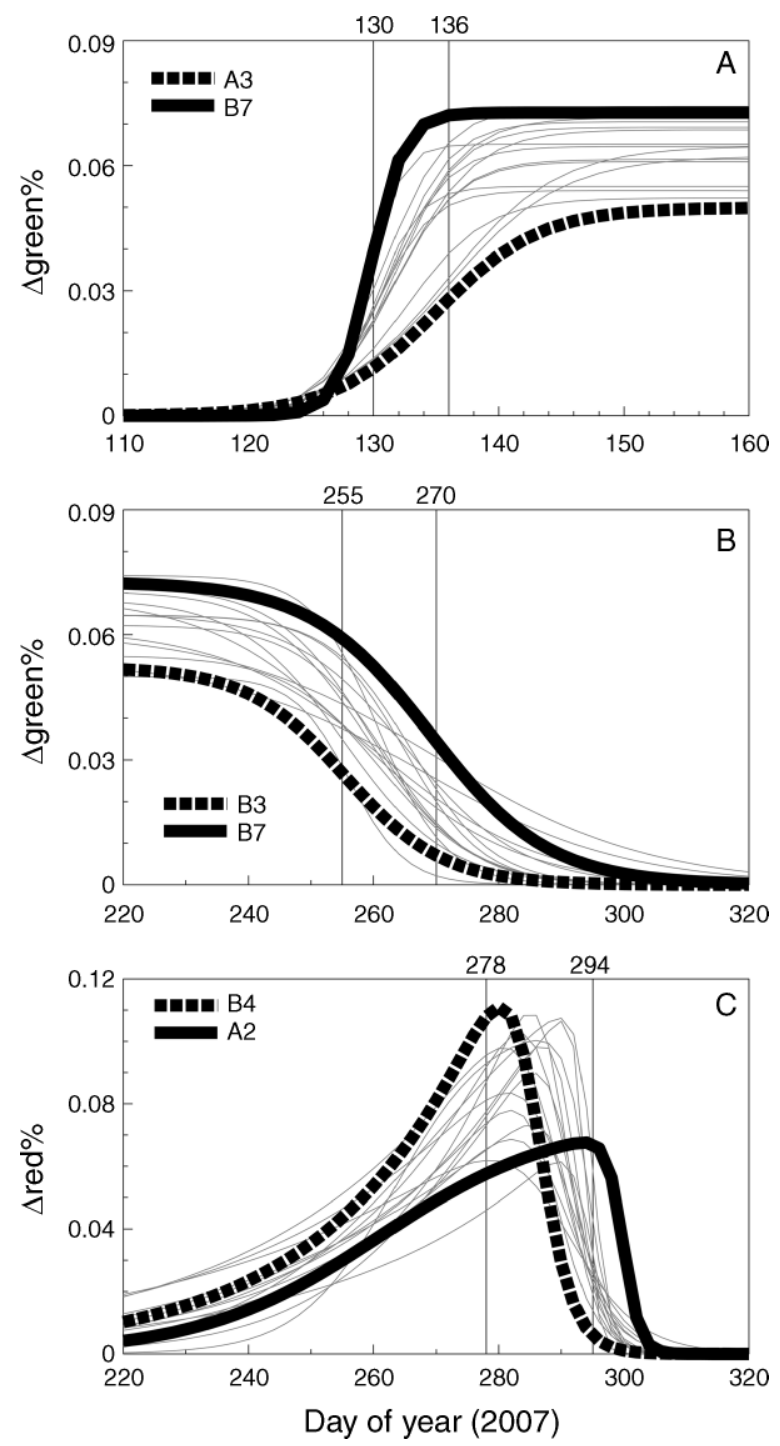

FIG. 3. Spatial variation in canopy development and senescence at Bartlett, as observed across 16 subregions of webcam imagery (fine lines; subregions indicated in Fig. 1). Solid and dashed heavy black lines highlight the extreme "early" and "late" subregions; vertical lines denote "early" and "late" dates of half-maximum $\Delta$ green $\%$ and peak $\Delta$ red $\%$ ( $\Delta$ channel\% notation indicates change in relative channel brightness above the dormant-season minimum).

green \% had dropped to its dormant-season minimum when the canopy was still mostly intact, as noted above.

By day 130, and thus more or less coincident with the initial stages of leaf development, we observed measurable canopy uptake of $\mathrm{CO}_{2}$ in the Bartlett eddy covariance flux record. However, as reported previously (Richardson et al. 2007), springtime increases in the development of whole-canopy photosynthetic capacity and daily integrated GPP (gross primary productivity) tended to proceed more slowly than the increases in green\%. Photosynthetic capacity reached a peak of about $27 \mu \mathrm{mol} \cdot \mathrm{m}^{-2} \cdot \mathrm{s}^{-1}$ between days 170 and 200 , and then began to slowly drop off as the summer progressed. However, even when autumn leaf coloration was at peak (day 280), the canopy maintained some photosynthetic capacity $\left(\approx 10 \mu \mathrm{mol} \cdot \mathrm{m}^{-2} \cdot \mathrm{s}^{-1}\right)$, which did not reach nearzero levels until day $\approx 300$.

\section{Variation across the deciduous canopy}

We subdivided the main ROI into 16 subregions to evaluate spatial variation in terms of the timing and rate of spring green-up, autumn senescence, and autumn coloration, using the logistic function given in Eq. 3 to characterize these patterns for each subregion, and looking at seasonal changes above the dormant-season base level given by parameter $a$ (i.e., $\Delta$ green $\%=$ green $\%-a$ ). This analysis indicated that in spring, increases in $\Delta$ green $\%$ occurred at about the same point in time for all subregions, but that the rate of development varied by nearly fourfold, with subregion B7 showing a rapid increase in $\Delta$ green $\%$ and subregion A3 showing a very slow increase in $\Delta$ green $\%$ (Fig. $3 \mathrm{~A}$ ). The date at which each subregion reached half-maximum $\Delta$ green $\%$ varied by almost a week, from day 130 to day 136 . Finally, the seasonal amplitude of $\Delta$ green $\%$ varied by about $50 \%$ between subregions B2 (which was slightly more green than subregion B7) and A3. Although the differences between subregions B7 and A3 might seem to suggest that an earlier half-maximum $\Delta$ green $\%$ was correlated with larger seasonal amplitude of $\Delta$ green $\%$, this correlation was not significant across the 16 subregions $(r=$ $-0.25, P=0.35)$.

Whereas spring green-up was largely completed over the course of a two-week period, green-down of the canopy in autumn progressed more slowly, requiring close to two months (Fig. 3B). There was also more pronounced spatial variation in autumn, with the date of half-maximum $\Delta$ green $\%$ varying by roughly two weeks, from day 255 for subregion B3 to day 270 for subregion A2. Finally, as was the case for the rate of green-up, the rate of green-down varied by more than three-fold across subregions.

The timing and peak intensity of autumn coloration varied across the canopy as well (Fig. 3C). Subregion B3 (which also had the earliest drop in $\Delta$ green $\%$ ) had the earliest $\Delta$ red\% peak, at day 278. Subregion B4 had the strongest $\Delta$ red $\%$ peak about two days later. Subregion A2 had the latest $\Delta$ red\% peak, at day 294 .

An interesting result to emerge from this analysis of spatial variability is that the amplitude (given by parameter $b$ ) of seasonal changes in green $\%$ was strongly correlated with the amplitude of the autumn red\% peak (Fig. 4). This may be a manifestation of differences among species (i.e., species with "greener" foliage in summer tend to develop more intensely "red" coloration in fall; at least for species that develop anthocyanins, this contention is supported by data in Table 1 of Lee et al. 2003), or it could be related to stress physiology, e.g., summer chlorosis as a precursor to diminished autumn coloration. This relationship, and our explanations for 


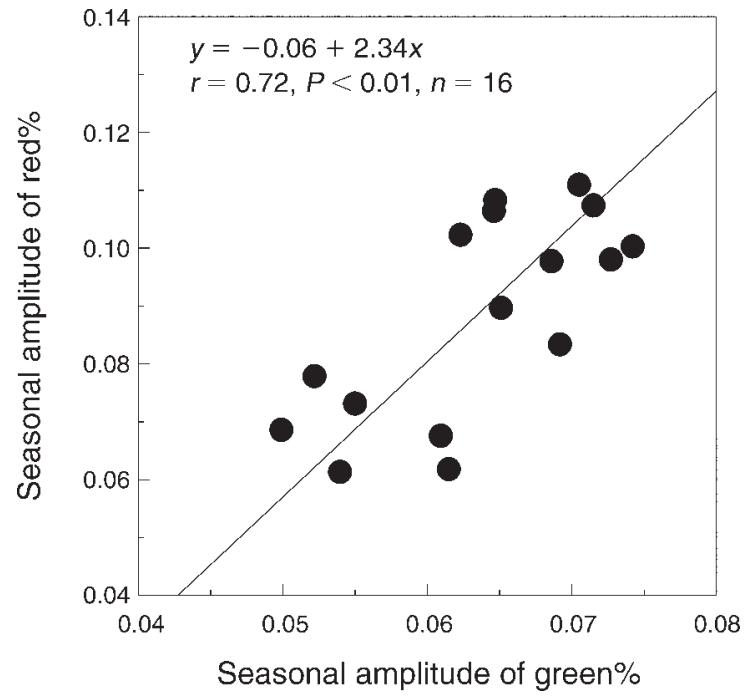

FIG. 4. Correlation between the seasonal amplitude of relative green channel brightness, which peaked in late spring, and the seasonal amplitude of relative red channel brightness, which peaked in autumn, across 16 subregions of webcam imagery from Bartlett. Amplitudes were determined from logistic curves (Eq. 3) fit to time series data, as illustrated in Fig. 3.

the underlying mechanisms, are proposed here as hypotheses for future investigation.

Our analysis provides insights into the variability in phenology across the canopy, and also gives some idea of the sampling uncertainty (though not in a rigorous statistical manner; we note that some subregions include crowns from a number of individuals, and that the effective size of each subregion varies according to the distance from the camera) that can be attributed to pointing the camera at a particular patch of forest. Furthermore, the patterns observed for the different subregions can be related to the species (and thus biology) of the trees dominant in each; for example, red maple (dominating B4) foliage typically changes color (bright reddish-purple) early in autumn, and drops its leaves early as well, whereas beech (dominating A2) foliage turns brownish yellow, rather than bright red, and is retained later in the autumn (Lee et al. 2003). An alternative to the gridded subregions we used would be to identify individual tree crowns. Ahrends et al. (2008) used this approach to identify three separate individuals of each ash and beech, and in this manner was able to look at phenological differences both between and within species. For Bartlett, identification of individual crowns would be easier if the camera was mounted higher above the canopy and angled more directly downward, which would also minimize potential artifacts associated with seeing one tree through the partially developed crown of another tree.

\section{Seasonal patterns of mixed and coniferous canopies}

In addition to the main ROI in the immediate foreground of the Bartlett images, we analyzed seasonal
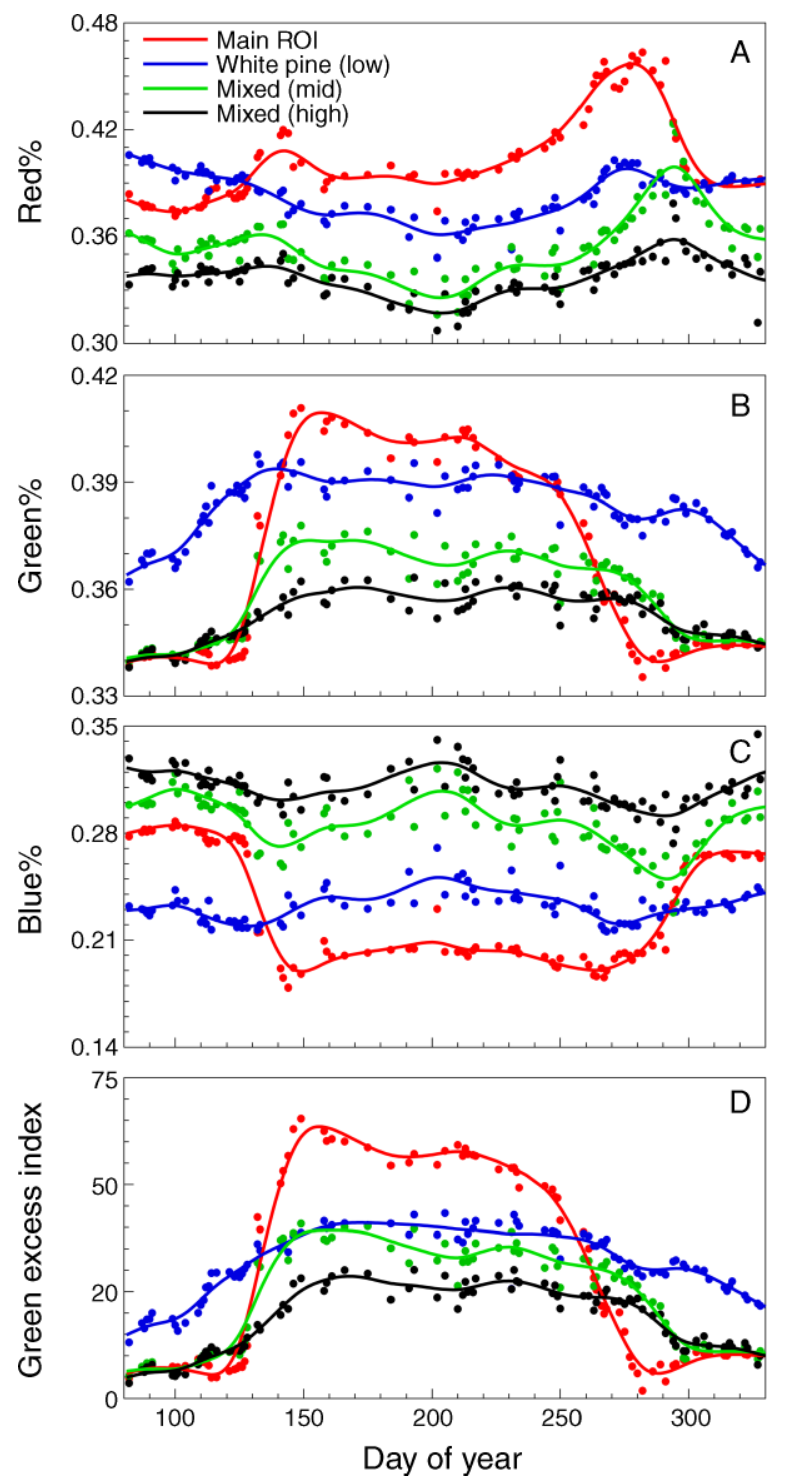

FIG. 5. Seasonal changes in relative brightness of (A) red, (B) green, and (C) blue channel for different regions of interest (see Fig. 1A) in Bartlett webcam imagery. (D) "Green excess" index $(2 \mathrm{G}-\mathrm{RBi})$ was calculated as $(2 \times$ green $\mathrm{DN})-($ red $\mathrm{DN}+$ blue DN). Lines indicate best-fit iterative smoothing splines (smoothing parameter $=25)$.

patterns for three additional ROIs (Fig. 1A), located at a distance from 1 to $4 \mathrm{~km}$ from the tower, and up to more than $300 \mathrm{~m}$ higher in elevation. Because camera views of the mid- and high-elevation stands were occasionally blocked by fog and low clouds, we restrict this analysis to images recorded on sunny days $(n=81)$. For each of the three color channels, the seasonal patterns at the more distant stands were less pronounced than for the main ROI (Fig. 5A-C), possibly because atmospheric effects muted the vibrancy of colors with increasing distance, but also because of the evergreen conifer component, particularly for the low-elevation 
pine stand. Whereas trees in the main ROI exhibited a pronounced autumn peak in red\%, and this was seen to some degree in the mid-elevation mixed stand, there was only the slightest autumn increase in red\% in either the low-elevation pine stand, or the high-elevation mixed stand (Fig. 5A). Even the low-elevation pine stand and the high-elevation mixed stand showed seasonal changes in green \%, but the seasonal amplitude of this signal was less than half that for the main ROI (Fig. 5B). Interestingly, the spring increase in green $\%$ in the lowelevation pine stand began around day 100 , which was earlier than the increase in green\% in any other stand, and not only predated budburst by any deciduous or conifer species, but even occurred in advance of snowmelt, which happened (based on measurements of soil temperature at $5 \mathrm{~cm}$ ) at about day 118 .

Although a strong seasonal signal in blue\% was observed for the main ROI, this pattern was not observed for the other stands (Fig. 5C). The "green excess" index (Richardson et al. 2007; see also Woebbecke et al. 1995), which we denote as 2G-RBi and calculate as $(2 \times$ green $\mathrm{DN})-($ red $\mathrm{DN}+$ blue $\mathrm{DN})$, showed seasonal patterns that largely mirrored those in green $\%$ for each stand analyzed. An exception was the low-elevation pine stand, where green\% alone indicated a more rapid development (day $\approx 100$ through day $\approx 130$ ) than $2 \mathrm{G}-\mathrm{RBi}($ day $\approx 100$ through day $\approx 150$ ). For both green $\%$ and $2 \mathrm{G}-\mathrm{RBi}$, however, autumn green-down occurred later in the mid- and high-elevation mixed stand than the main ROI. Other indices, including twochannel normalized difference indices (e.g., [green\% red\%]/[green $\%+$ red\%]) were investigated but found not to contribute new information. There are, of course, only a limited number of indices that can be constructed from three channels of information, and a related problem is that the mapping from RGB space back to the spectral characteristics of the object being observed is non-unique: two objects that appear to be the same color could easily absorb and reflect specific wavelengths quite differently. Similarly, for multichannel indices, two objects that appear different colors may have the same index value, which in some cases may make linking index values back to physiological responses or mechanisms difficult.

For the spruce-dominated Howland forest, day-today variations in relative channel brightness were much more pronounced than at Bartlett (compare Fig. 6A with Fig. 2), and these tended to obscure any seasonal signal. Although canopy shadows are much more evident at Howland than Bartlett on sunny days, the greater variability at Howland does not appear to be the result of differences in canopy geometry between deciduous and coniferous forests. Rather, the internal processing of images by each camera, and sensitivity to different lighting conditions, appear to be key factors. By visually classifying the pictures from both sites into "sunny," "cloudy," and "precipitation" days, we were able to identify excessively dark images of the Howland canopy on bright, overcast days as the primary source of this variability. In fact, restricting the analysis to images recorded on days that were classified as "sunny," or by automatically filtering the images for unfavorable conditions (red DN $>25$ and green $\mathrm{DN}>35$ to filter out overly dark images, with the images passing these objective criteria essentially the same set as those classified subjectively as "sunny"; by adding the additional filter blue DN $<30$, we eliminated images with snow covering the canopy) resulted in a $\approx 75 \%$ decrease in the day-to-day variability of the seasonal signal, as measured by individual relative channel brightness (e.g., green\%; see Fig. 6A), and a 50\% decrease in the variability of green excess index, 2G$\mathrm{RBi}$. (We are investigating whether changing some of the configuration options on the Howland camera might eliminate the need for this kind of ad hoc filtering, and whether the objective filtering criteria described above are site specific or can be applied to digital images from other research sites.)

At Howland, the green excess index captured a strong seasonal pattern of increasing greenness above the wintertime minimum beginning around day 100 , rising to a peak at day 180 , and then slowly declining to the wintertime minimum by day 330 (Fig. 6B); seasonal patterns at this site were thus similar to those for the low-elevation pine stand at Bartlett. It is highly unlikely that these patterns are driven by seasonal variation in the amount of green understory vegetation, since the high leaf area index $(\mathrm{LAI} \approx 5.5)$ at Howland results in very low transmittance of solar radiation to the understory ( $\approx 6 \%$ of incident PPFD), and the understory is, even in mid-summer, extremely sparse. That the spring rise in green excess at Howland began nearly a month before budburst of hardwood species (day 128), and more than a month and a half before budburst of conifer species (day 149), is significant because it indicates that the seasonal pattern is not driven solely by the development of new foliage or senescence of old foliage, but rather by biochemical changes in the composition of existing foliage, most likely involving springtime regeneration and autumn breakdown of chlorophyll and other pigments: as shown in previous studies, foliar chlorophyll concentrations of conifers can be reduced by $\approx 40 \%$ during winter (Billow et al. 1994).

The observed greening-up of conifer stands is thus related to a functionally different signal compared that in deciduous stands, although in both cases the onset of spring green-up appears to roughly coincide with the onset of photosynthetic activity. At Howland, the seasonal trend in green excess closely paralleled that of canopy-level GPP, as determined from eddy covariance measurements of $\mathrm{CO}_{2}$ exchange made at the site (Fig. 6B). Daily green excess index (filled circles in Fig. 6B) and daily GPP were linearly correlated over the course of the year $(r=0.80, P \leq 0.001, n=360$ for the unfiltered 2G-RBi time series, $r=0.95, P \leq 0.001, n=153$ for the filtered $2 \mathrm{G}-\mathrm{RBi}$ time series). These patterns contrast 

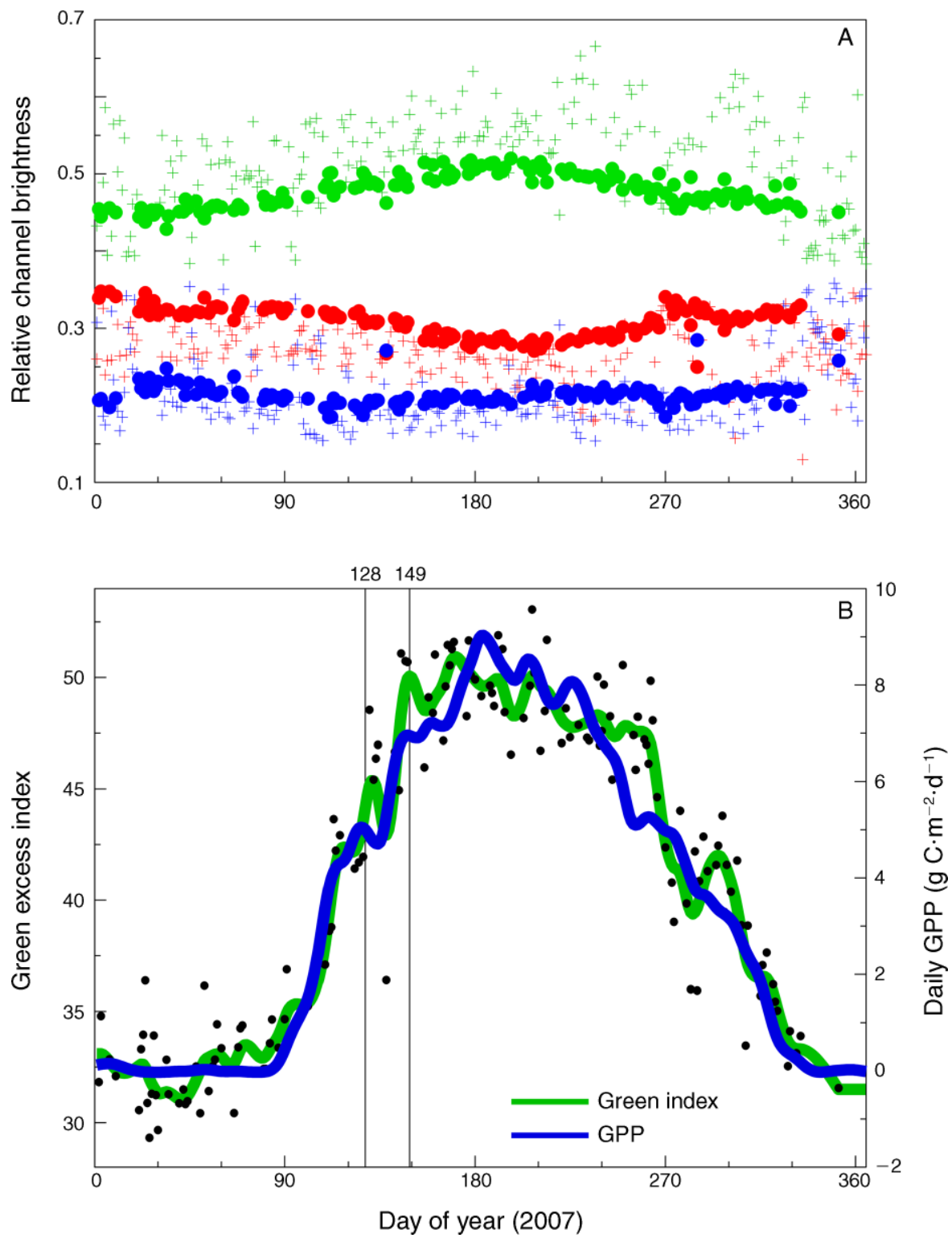

FIG. 6. (A) Seasonal variation in relative color channel brightness (red\%, green $\%$, blue $\%$ ), based on webcam imagery from Howland. Circles indicate data points that passed filtering criteria; "plus" symbols (+) indicate data points that did not meet these criteria. (B) Seasonal variation in "green excess" index (2G-RBi) and daily GPP (inferred from eddy covariance measurements of surface-atmosphere $\mathrm{CO}_{2}$ exchange). Black circles indicate midday green excess index values, derived from filtered red DN, green $\mathrm{DN}$, and blue DN time series; colored lines are best-fit iterative smoothing splines (smoothing parameter $=15$ ). Vertical lines denote budburst dates of dominant hardwood (day 128) and conifer (day 149) species, based on field observations.

somewhat with results reported above for Bartlett, where springtime increases in canopy-level photosynthetic capacity lagged behind foliar development, as has been noted in leaf-level studies (e.g., Morecroft et al. 2003). The fact that we can detect physiological activity following winter dormancy earlier in coniferous stands is analogous to the observation, based on eddy covariance measurements, that onset of photosynthetic uptake began earlier at Howland (day $\approx 90$ ) than Bartlett (day $\approx 130$ ) (see also Richardson et al. 2009).

\section{Patterns of interannual variation in a deciduous forest phenology}

We qualitatively evaluated interannual variation in the timing of spring and autumn by visual inspection of the camera images. For example, on day 122 in 2006, leaves were, for the first time, visible on many trees within the ROI; at this point, 364 degree-days (above $0^{\circ} \mathrm{C}$ base) had been accumulated. By comparison, on this day in 2007 the canopy was still leafless: the same transition would not occur until at least a week later, on 

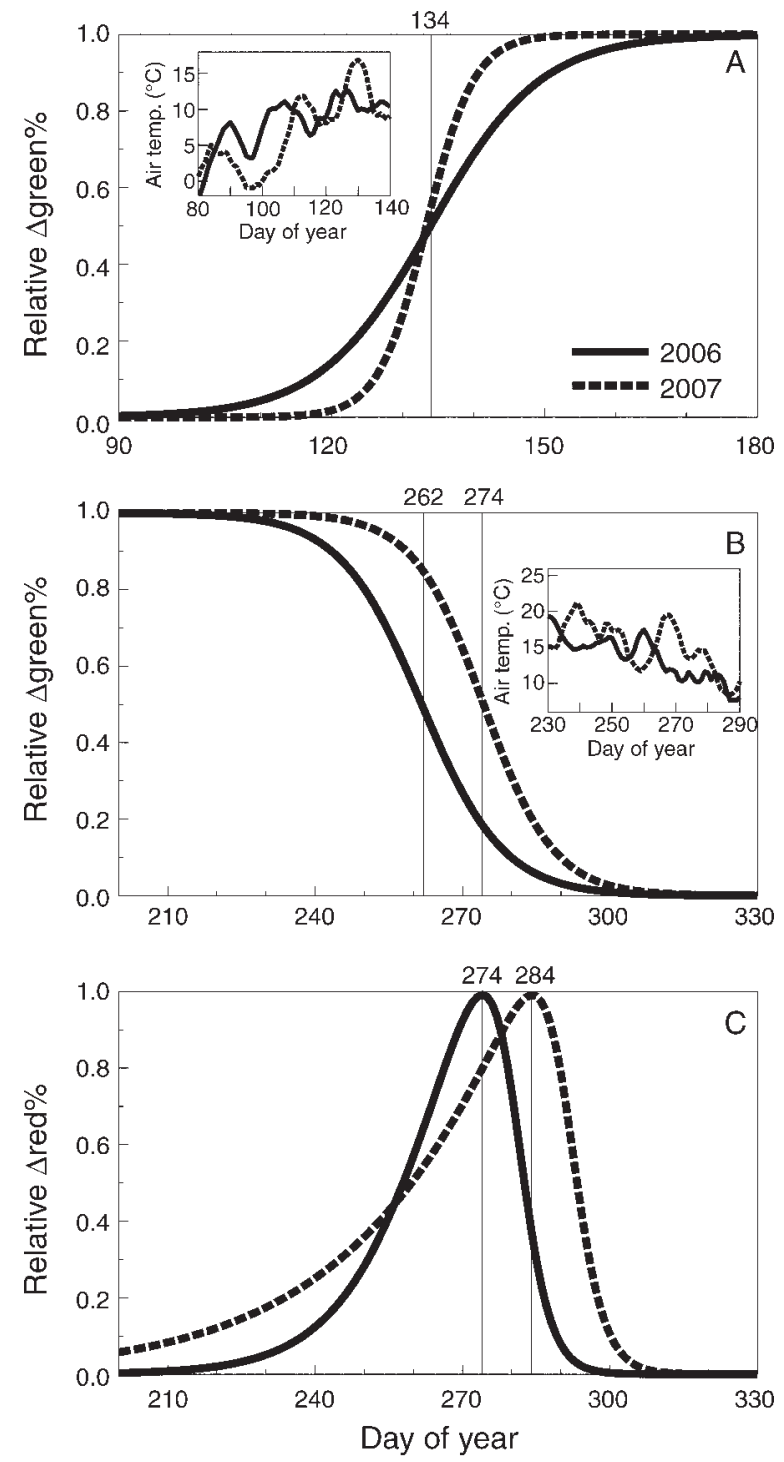

FIG. 7. Interannual variation in spring and autumn phenology at Bartlett, based on two years of webcam imagery and characterized by logistic curves (Eq. 3) fit to time series data. The $y$-axis shows the seasonal trajectory on a normalized $(0-1)$ scale, where 0 is dormant season minimum and 1 is active season maximum. Vertical lines denote dates of half-maximum green\% (A, B) and autumn red\% peak (C). Insets in panels (A) and $(\mathrm{B})$ show seven-day smoothed air temperature $\left({ }^{\circ} \mathrm{C}\right)$ time series.

day 129, when an almost identical number (368) of degree-days had been accumulated. In autumn, the canopy appeared close to bare by day 286 in 2006; on this day in 2007, however, very few leaves had yet been dropped: another nine days would pass before most of the trees had no leaves left.

These patterns can be captured quantitatively by comparing the logistic curves (Eq. 3) fit separately to each year of data. To facilitate comparison, the seasonal amplitude is set to 1 (i.e., Eq. 3 with parameters $a=0$ and $b=1$ ), and results are presented in terms of the relative amplitude (e.g., relative $\Delta$ green\%). From this we see that, although the start of green-up occurred about 7 days later in 2006 than 2007, green-up proceeded about twice as fast in 2007, and as a result, the date of halfmaximum relative $\Delta$ green $\%$ (day 134) was essentially the same in both years (Fig. 7A). The difference between 2006 and 2007 in the timing and rate of spring onset can be explained by large temperature differences between the two years. From day 85 through day 110, the mean daily air temperature was much warmer in $2006\left(7.7^{\circ} \mathrm{C}\right)$ compared to $2007\left(2.4^{\circ} \mathrm{C}\right)$. More than three times as many degree-days were accumulated over this period in 2006 (184 degree-days) compared to 2007 (61 degreedays). Between day 111 and day 126, temperatures were essentially equal in 2006 and 2007 (166 accumulated degree-days in each year). Between day 127 and day 135, the mean daily air temperature was much colder in 2006 $\left(9.8^{\circ} \mathrm{C}\right)$ compared to $2007\left(16.0^{\circ} \mathrm{C}\right)$, and $60 \%$ more degree-days were accumulated in 2007 (144 degree-days) compared to 2006 (88 degree days). Thus, in 2007 a prolonged cold spell in early spring resulted in delayed leaf out, but later a brief period of great warmth enabled very rapid leaf development. This argument is substantiated by the fact that when a simple, sigmoid-shaped phenological model (driven by accumulated heating degree days above $4^{\circ} \mathrm{C}$ ), as parameterized by Richardson et al. (2006) using phenological observations on northern hardwood species from the nearby $(\approx 30 \mathrm{~km}$ to the southwest) Hubbard Brook LTER, was run for Bartlett, a much earlier (by slightly more than a week) initiation of the onset of canopy development was predicted for 2006 compared to 2007 . The model also predicted that once development began in 2007, it proceeded rapidly, consistent with the webcam data.

In autumn, green-down occurred almost two weeks later in 2007 (day 274) than in 2006 (day 262), but the rate of decrease in relative $\Delta$ green $\%$ was similar for the two years (Fig. 7B). Finally, the autumn peak in relative $\Delta$ red\% occurred 10 days later in 2007 (day 284) than 2006 (day 274) (Fig. 7C), and the duration of autumn coloration (number of days with relative $\Delta$ red\% $>0.5$ ) was almost 40\% longer in 2007 (34 days) than 2006 (25 days). Models to explain autumn phenology are less well developed than those for spring (Schaber and Badeck 2003), and both temperature and photoperiod are thought to be important factors, but we note that the mean daily air temperature from day 230 to day 280 was more than $2^{\circ} \mathrm{C}$ warmer in $2007\left(16.3^{\circ} \mathrm{C}\right)$ than in 2006 $\left(14.2^{\circ} \mathrm{C}\right)$, thus offering a partial explanation for the delayed senescence and abscission in 2007. This interpretation is consistent with predictions of the Richardson et al. (2006) autumn phenology model, driven by accumulated chilling degree days below $20^{\circ} \mathrm{C}$ and parameterized using Hubbard Brook data as described above, which, when run for Bartlett, predicts delayed abscission (by about 10 days) in 2007 compared to 2006. Year-to-year variation in precipitation and, consequently, soil water content (SWC; our data indicate that from 
day 160 through almost the very end of the growing season, SWC in the $0-10 \mathrm{~cm}$ horizon was $\approx 25 \%$ lower in 2007 than 2006), may also play a role in the regulating variation in intensity and timing of canopy coloration, particularly in autumn (and potentially in the context of spatial variability in SWC playing a role in the patterns shown in Fig. 4).

Although canopy transmittance measurements revealed similar patterns (i.e., delayed but more rapid development, and delayed abscission, in 2007 compared to 2006), there is one important distinction. With the broadband radiometric data alone, it is difficult (if not impossible) to distinguish between a photosynthetically active, green canopy, and a brightly colored, senescing canopy with greatly reduced photosynthetic capacity (e.g., Sakai et al. 1997). This is underscored by results from the low-elevation pine stand at Bartlett, and the spruce-fir canopy at Howland, where spring green-up and autumn green-down were both detected despite no appreciable change in the amount of foliage present. The ability to detect not only whether foliage is being displayed, but rather the degree of greenness of that foliage, is an important advancement that should improve understanding of relationships between measures of growing-season length and $\mathrm{CO}_{2}$ uptake potential.

\section{Summary and Conclusions}

We have used two years of digital camera imagery from a deciduous, northern hardwood forest (Bartlett), and one year of imagery from an evergreen conifer forest (Howland) to quantify spatial and temporal variation in canopy phenology. Building on the results of earlier work, we have shown with these data (1) that spring and autumn phenology vary spatially across a canopy; (2) that in addition to the dominant "summer green" signal, a clear "autumn red" signal can be extracted for deciduous species; (3) that evergreen conifers become markedly greener in early spring, and less green in autumn, and that this appears to parallel changes in primary productivity; (4) that interannual variation in the timing, and also the rate, of green-up and senescence, can be both visually and quantitatively assessed from digital camera imagery.

Characterizing the timing and intensity of changes in foliar coloration in this manner is potentially useful as a means of monitoring forest health, particularly with regard to stress imposed by factors such as drought and insect outbreaks or longer-term impacts from climate change. This could be important both from a land management perspective and in terms of economic returns. For example, the strength of New England's autumn tourism industry is directly tied to the vibrancy of fall colors, and quantitative, real-time tracking (and perhaps even forecasting) of peak colors would be valuable for targeting when and where tourists should go for the best viewing experience.
In Europe, there is a long tradition of both amateur and professional naturalists maintaining detailed phenological records (Sparks and Menzel 2002); in North America, comparable data sets are relatively rare, although the USA-NPN is actively working towards the development of an observer-based monitoring network (Betancourt et al. 2005). Future (and complementary) efforts, particularly within NEON, where it is anticipated that cameras will be installed on all Fundamental Sentinel Unit instrument towers, will offer unique opportunities for automated, high-frequency, continental-scale monitoring of phenology across a range of ecosystems. There are also opportunities to leverage existing infrastructure and equipment (webcams and radiometric instruments) installed at existing eddy covariance flux measurement sites (e.g., AmeriFlux and, more broadly, FLUXNET), and synthesis efforts to link phenology with the seasonal cycles of carbon and water exchange are underway (e.g., Wingate et al. 2008; see also the PhenoCam project [more information available online]). ${ }^{7}$

\section{ACKNOWLedgments}

Support for this research was provided by the Northeastern States Research Cooperative, the U.S. Department of Energy's Office of Science (BER) through the Northeastern Regional Center of the National Institute for Climatic Change Research and the Terrestrial Carbon Program under Interagency Agreement No. DE-AI02-07ER64355, and the NASA Terrestrial Carbon (grant no. CARBON/04-0120-0011) and IDS (grant no. NNG04GH75G) programs. Research at Bartlett and Howland is supported by the USDA Forest Service's Northern Global Change program and Northern Research Station. Meteorological and radiometric data, as well as $\mathrm{CO}_{2}$ and $\mathrm{H}_{2} \mathrm{O}$ fluxes, for the both sites are available at the AmeriFlux Web site (see footnote 6) subject to AmeriFlux Fair-use policies. This is a publication of the Northeastern Regional Phenology Network (NE-RPN).

\section{Literature Cited}

Ahrends, H. E., R. Brügger, R. Stöckli, J. Schenk, P. Michna, F. Jeanneret, H. Wanner, and W. Eugster. 2008. Quantitative phenological observations of a mixed beech forest in northern Switzerland with digital photography. Journal of Geophysical Research-Biogeosciences 113:G04004. [doi: 10. 1029/2007JG000650]

Betancourt, J. L., M. D. Schwartz, D. D. Breshears, D. R. Cayan, M. D. Dettinger, D. W. Inouye, E. Post, and B. C. Reed. 2005. Implementing a U.S. National Phenology Network. EOS Transactions AGU 86:539-541.

Billow, C., P. Matson, and B. Yoder. 1994. Seasonal biochemical changes in coniferous forest canopies and their response to fertilization. Tree Physiology 14:563-574.

Booth, D. T., and S. E. Cox. 2008. Image-based monitoring to measure ecological change in rangeland. Frontiers in Ecology and the Environment 6:185-190.

Cleland, E. E., N. R. Chiariello, S. R. Loarie, H. A. Mooney, and C. B. Field. 2006. Diverse responses of phenology to global changes in a grassland ecosystem. Proceedings of the National Academy of Sciences (USA) 103:13740-13744.

Cleland, E. E., I. Chuine, A. Menzel, H. A. Mooney, and M. D. Schwartz. 2007. Shifting plant phenology in response to global change. Trends in Ecology and Evolution 22:357-365.

\footnotetext{
${ }^{7}\langle$ http://phenocam.unh.edu $\rangle$
} 
Crimmins, M. A., and T. M. Crimmins. 2008. Monitoring plant phenology using digital repeat photography. Environmental Management 41:949-958.

Desai, A. R., A. D. Richardson, A. M. Moffat, J. Kattge, D. Y. Hollinger, A. Barr, E. Falge, A. Noormets, D. Papale, M Reichstein, and V. J. Stauch. 2008. Cross site evaluation of eddy covariance GPP and RE decomposition techniques. Agricultural and Forest Meteorology 148:821-838.

Gazal, R., M. A. White, R. Gillies, E. Rodemaker, E. Sparrow, and L. Gordon. 2008. GLOBE students, teachers, and scientists demonstrate variable differences between urban and rural leaf phenology. Global Change Biology 14:15681580 .

Graham, E. A., M. P. Hamilton, B. D. Mishler, P. W. Rundel, and M. H. Hansen. 2006. Use of a networked digital camera to estimate net $\mathrm{CO}_{2}$ uptake of a desiccation-tolerant moss. International Journal of Plant Sciences 167:751-758.

Graham, E. A., E. M. Yuen, G. F. Robertson, W. J. Kaiser, M. P. Hamilton, and P. W. Rundel. 2009. Budburst and leaf area expansion measured with a novel mobile camera system and simple color thresholding. Environmental and Experimental Botany 65:238-244.

Hague, T., N. D. Tillett, and H. Wheeler. 2006. Automated crop and weed monitoring in widely spaced cereals. Precision Agriculture 7:21-32.

Hollinger, D. Y., et al. 2004. Spatial and temporal variability in forest-atmosphere $\mathrm{CO}_{2}$ exchange. Global Change Biology 10:1689-1706.

Jenkins, J. P., A. D. Richardson, B. H. Braswell, S. V. Ollinger, D. Y. Hollinger, and M. L. Smith. 2007. Refining light-use efficiency calculations for a deciduous forest canopy using simultaneous tower-based carbon flux and radiometric measurements. Agricultural and Forest Meteorology 143:64-79.

Lechowicz, M. J. 1984. Why do temperate deciduous trees leaf out at different times? Adaptation and ecology of forest communities. American Naturalist 124:821-842.

Lee, D. W., J. O'Keefe, N. M. Holbrook, and T. S. Feild. 2003. Pigment dynamics and autumn leaf senescence in a New England deciduous forest, eastern USA. Ecological Research 18:677-694.

Luscier, J. D., W. L. Thompson, J. M. Wilson, B. E. Gorham, and L. D. Dragut. 2006. Using digital photographs and object-based image analysis to estimate percent ground cover in vegetation plots. Frontiers in Ecology and the Environment 4:408-413.

Morecroft, M. D., V. J. Stokes, and J. I. L. Morison. 2003. Seasonal changes in the photosynthetic capacity of canopy oak (Quercus robur) leaves: the impact of slow development on annual carbon uptake. International Journal of Biometeorology 47:221-226.

Morisette, J. T., A. D. Richardson, A. K. Knapp, J. I. Fisher, E. A. Graham, J. Abatzoglou, B. E. Wilson, D. D. Breshears,
G. M. Henebry, J. M. Hanes, and L. Liang. 2009. Tracking the rhythm of the seasons in the face of global change: phenological research in the 21 st Century. Frontiers in Ecology and the Environment, in press. [doi: 10.1890/070217]

Parmesan, C. 2007. Influences of species, latitudes and methodologies on estimates of phenological response to global warming. Global Change Biology 13:1860-1872.

Peñuelas, J., I. Filella, and P. Comas. 2002. Changed plant and animal life cycles from 1952 to 2000 in the Mediterranean region. Global Change Biology 8:531-544.

Richardson, A. D., A. S. Bailey, E. G. Denny, C. W. Martin, and J. O'Keefe. 2006. Phenology of a northern hardwood forest canopy. Global Change Biology 12:1174-1188.

Richardson, A. D., D. Y. Hollinger, D. B. Dail, J. T. Lee, J. W. Munger, and J. O'Keefe. 2009. Influence of spring phenology on seasonal and annual carbon balance in two contrasting New England forests. Tree Physiology 29:321-331.

Richardson, A. D., J. P. Jenkins, B. H. Braswell, D. Y. Hollinger, S. V. Ollinger, and M. L. Smith. 2007. Use of digital webcam images to track spring green-up in a deciduous broadleaf forest. Oecologia 152:323-334.

Sakai, R. K., D. R. Fitzjarrald, and K. E. Moore. 1997. Detecting leaf area and surface resistance during transition seasons. Agricultural and Forest Meteorology 84:273-284.

Schaber, J., and F. W. Badeck. 2003. Physiology-based phenology models for forest tree species in Germany. International Journal of Biometeorology 47:193-201.

Schwartz, M. D., R. Ahas, and A. Aasa. 2006. Onset of spring starting earlier across the Northern Hemisphere. Global Change Biology 12:343-351.

Slaughter, D. C., D. K. Giles, and D. Downey. 2008. Autonomous robotic weed control systems: a review. Computers and Electronics in Agriculture 61:63-78.

Sparks, T. H., and A. Menzel. 2002. Observed changes in seasons: an overview. International Journal of Climatology 22:1715-1725.

Turner, D. P., S. Urbanski, D. Bremer, S. C. Wofsy, T. Meyers, S. T. Gower, and M. Gregory. 2003. A cross-biome comparison of daily light use efficiency for gross primary production. Global Change Biology 9:383-395.

White, M. A., and R. R. Nemani. 2006. Real-time monitoring and short-term forecasting of land surface phenology. Remote Sensing of Environment 104:43-49.

Wingate, L., A. D. Richardson, J. F. Weltzin, K. N. Nasahara, and J. Grace. 2008. Keeping an eye on the carbon balance: linking canopy development and net ecosystem exchange using a webcam. FluxLetter (the Newsletter of FLUXNET) 1(2):14-17.

Woebbecke, D. M., G. E. Meyer, K. Vonbargen, and D. A. Mortensen. 1995. Color indexes for weed identification under various soil, residue, and lighting conditions. Transactions of the ASAE 38:259-269. 